\title{
CAPITALISMO HUMANISTA: UMA NOVA ÉTICA UNIVERSALISTA PARA A ECONOMIA DE MERCADO
}

\author{
Ricardo Hasson Sayeg* \\ Daniel Jacomelli Hudler**
}

\section{RESUMO:}

Economia de mercado funda-se no capitalismo liberal. Diante dos desafios da pósmodernidade (legitimidade, representatividade, concentração de renda), aventa-se a possibilidade de construção dogmático-jurídica e epistemológica de um capitalismo humanizado, com esteio na fraternidade, integrado pela ética, a partir da estrutura normativa dos Direitos Humanos. Hipóteses: i) capitalismo não se esgota enquanto resposta para distribuição de bens e serviços; ii) ordenamento jurídico brasileiro incorpora ética universalista humanista. Emprega-se o método hipotético-dedutivo, auxiliado da pesquisa bibliográfica. Conclui-se: 1 - capitalismo não se esgotou na compreensão (neo)liberal (século $\mathrm{XX}$ ), pois conjunto de valores pode ser reformulado; 2 - ordenamento jurídico brasileiro adota ética universalista humanista.

Palavras-chave: Capitalismo Humanista. Economia e Direito. Ética empresarial. Neoliberalismo. Fraternidade.

\section{HUMANIST CAPITALISM: A NEW UNIVERSALIST ETHICS FOR THE MARKET ECONOMY}

\begin{abstract}
:
Market economy is based on liberal capitalism. Faced with the challenges of postmodernity (legitimacy, representativeness, concentration of income), the possibility of a dogmaticjuridical and epistemological construction of a humanized capitalism is being considered,
\end{abstract}

\footnotetext{
* Diretor do Programa de Pós-Graduação - Mestrado e Doutorado da Universidade Nove de Julho UNINOVE e Professor Titular de Direito Quântico Empresarial da mesma IES. Professor Livre Docente de Direito Econômico da Faculdade de Direito da Pontifícia Universidade Católica de São Paulo - PUC-SP, tendo como principal linha de pesquisa o Capitalismo Humanista correspondente à Dimensão Econômica dos Direitos Humanos. Doutor e Mestre em Direito Comercial pela PUC-SP. Coordenador da Área de Direito Econômico do Departamento de Ciências Tributárias, Econômicas e Comerciais da Faculdade de Direito da PUC-SP. Líder do Grupo de Pesquisa Capitalismo Humanista certificado pelo CNPq atuante na PUC-SP. Membro do Conselho Superior da CAPES do Ministério da Educação (2018-2020) e (2021-2023). Ganhador do Prêmio Jurista do Ano conferido pela Ordem dos Economistas do Brasil - OEB (2017). Ganhador da Medalha Anchieta e Diploma de Gratidão da Cidade de São Paulo. Condecorado com Distinção pela Ordem do Mérito Judiciário do Superior Tribunal Militar. Teórico inspirador da PEC 383/2014, proposta para alterar o disposto no artigo 170 da Constituição Federal de 1988, objetivando inserir a observância aos Direitos Humanos entre os princípios que regem a ordem econômica. Filósofo do Direito Quântico. Guest Professor at California Western School of Law (San Diego USA) of Human Rights. Conselheiro do Conselho Superior de Assuntos Jurídicos e Legislativos CONJUR da Federação das Indústrias do Estado de São Paulo - FIESP. Titular da Cadeira 32 da Academia Paulista de Direito, da qual é Presidente do Conselho Fiscal. E-mail: ricardo@ hslaw.com.br

** Doutorando e Mestre em Direito pela Universidade Nove de Julho (UNINOVE). Especialista em Direito Processual Civil e Bacharel em Direito (MACKENZIE). Ex-editor Assistente das revistas científicas Prisma Jurídico e Thesis Juris. Experiência internacional pela Universidade da Coruña (UDC/Espanha) em Globalización \& Empresa: una visión Europea. Advogado. Professor e Pesquisador em Direito e Desenvolvimento; Empresas e Direitos Humanos; Economia e Direito. E-mail: djhudler@gmail.com
} 
supported by fraternity, integrated by ethics, from the normative structure of Human Rights. Hypotheses: i) capitalism is not exhausted as a response to the distribution of goods and services; ii) Brazilian legal system incorporates universalist humanist ethics. The hypothetical-deductive method is used, aided by bibliographical research. It concludes: 1 capitalism is not exhausted in the (neo)liberalism (20th century), as every set of values can be reformulated; 2 - Brazilian legal system adopts universalist humanist ethics.

Keywords: Humanistic Capitalism. Law \& Economics. Business \& Ethics. Neoliberalism. Fraternity.

\section{Introdução}

Como alocar riquezas e distribuir bens e serviços escassos para melhor atendimento das necessidades humanas? Esse é um problema estudado há séculos por economistas, filósofos e juristas. As respostas foram tão variadas quanto a própria história da humanidade, tendo prevalecido em nível global o capitalismo em razão da afirmação dos Direitos Humanos, particularmente, a liberdade individual.

O capitalismo é o sistema econômico consagrador da liberdade na medida em que tem nela seu próprio fundamento, sob o ponto de vista filosófico e econômico.

Durante os últimos séculos, o processo de desenvolvimento humano se sedimenta pela estrada do capitalismo, enquanto uma ideologia dotada de um conjunto de valores do liberalismo econômico, que surgiu como uma resposta duradoura e secular para a sua estruturação material.

O avanço tecnológico das últimas décadas trouxe benefícios incontestáveis. Como constatado pelo Banco Mundial (WORLD BANK, 2020), a expectativa de vida mundial per capita, em 1960, era de 53 anos e, em 2018, subiu para 73, como resultado do desenvolvimento do campo da medicina, da produção de alimentos e de uma melhora generalizada da renda e do acesso a bens e serviços. O ser humano, hoje, vive por mais tempo e com uma qualidade de vida superior, tendo sido esta a principal razão pela qual foi rasgada a cortina de ferro no leste europeu.

De outro lado, o mundo caminhou não apenas do ponto de vista tecnológico, mas sobretudo filosófico, a partir do enfrentamento de indagações mais profundas sobre as próprias relações humanas e sua fundamentação ética, inspiradas na constatação de externalidades econômicas negativas do aprofundamento das desigualdades e, assim, da pobreza e da marginalização. 
Não é por outro motivo que, no século $\mathrm{XX}$, a partir do choque político e ideológico de três modelos antagônicos de sociedade - capitalista, socialista e nazifascista -, é que prevaleceu, em última análise, os princípios e as regras jurídicas inerentes à Democracia, sob a premissa da inclusão e participação de todos, que se coloca no âmago de uma economia de mercado direcionada por um capitalismo em nível global.

No entanto, as externalidades econômicas e sociais negativas relacionadas ao início da industrialização e das primeiras revoluções tecnológicas não foram totalmente eliminadas, de modo que se torna pertinente a retomada do questionamento sempre presente e atual sobre o ajustamento do próprio capitalismo e suas bases filosóficas e econômicas. Cabe aos estudiosos a função de compreendê-lo e aperfeiçoá-lo para os desafios da pós-modernidade, notadamente diante do amadurecimento da consciência global de observância multidimensional dos Direitos Humanos.

A partir desta justificativa, na perspectiva nacional, elaboram-se as seguintes indagações e hipóteses para o presente estudo seminal: i) o capitalismo se esgotou enquanto resposta secular sobre a alocação da produção e distribuição de bens e serviços escassos?; ii) o ordenamento jurídico brasileiro adota normativamente uma ética universalista humanista?

Assim, o presente estudo estabelece como objeto a relação entre Economia Liberal, Ética, Direitos Humanos, tendo por referencial teórico a literatura formada sobre Capitalismo Humanista. Traça por diretrizes os seguintes objetivos: a) identificar o que seria o capitalismo enquanto sistema de valores e os limites do capitalismo liberal; b) verificar a relação entre o capitalismo e o humanismo, a partir de reflexões jurídicas, éticas e econômicas. A metodologia adotada se funda no método hipotético-dedutivo, auxiliado pela pesquisa de revisão de literatura, como meio para apresentar uma crítica reflexiva sobre o problema e as hipóteses ora apresentados.

\section{Capitalismo liberal}

$\mathrm{Na}$ atualidade, pressupõe-se a noção de que o modelo de mercado está condicionado a certos elementos sociais, culturais e históricos. Neste passo, os estudos embrionários de 
Economia Política, cujo objeto eram as relações de produção e distribuição de bens e serviços, têm como marco teórico os pensadores do século XVII e XVIII, os quais foram estimulados em um contexto de profundo descontentamento em relação às fórmulas políticas estabelecidas pelo Estado moderno (absoluto), no que toca à condução das relações econômicas - hoje, chamadas de políticas mercantilistas - que ocorriam no espaço geopolítico europeu de comércio internacional a partir do século XIV.

Segundo o economista americano Leo Huberman (1986), defendia-se muito mais um postulado político sobre a economia do que propriamente um estudo sistemático, dotado de um rigor científico acerca de políticas econômicas. Nesse contexto específico, e dentro das limitações metodológicas da época, os primeiros rudimentos de uma teoria das relações econômicas foram expressados pela chamada Teoria da balança de comércio - pela qual, assumiu-se que o objetivo do Estado era atingir riqueza material por meio do acúmulo de metais considerados preciosos.

Esse objetivo era implementado tanto por meio da exploração direta, a partir do fomento nacional em uma parceria burguesia-Estado para consolidação da relação exploratória de metrópole-colônia, quanto por medidas indiretas, como a tributação sobre a exploração ou da produção de bens, a partir da comercialização de produtos com custos de produção mais baixos, para trocá-los com outras nações.

Posteriormente, essa compreensão foi criticada por pensadores oriundos da própria burguesia, os quais inauguraram uma nova perspectiva filosófica sobre as relações econômicas e a respectiva incorporação desses pensamentos ao sistema jurídico, fundado na conquista dos direitos individuais de liberdade que garantiram certa oposição ao monopólio econômico e à intervenção do Estado nesses mercados.

Neste passo, a primeira versão de direitos atrelados àquela concepção liberal incorporou, no mínimo, quatro noções econômicas básicas, segundo José Eduardo Faria e Rolf Kuntz (2002): $i$ - autorregulação do mercado: os mercados tendem a se ajustar automaticamente ou "naturalmente", noção esta que foi reforçada pela primeira descrição do comércio internacional enquanto um sistema de vasos comunicantes; $i i$ - especialização: as economias tendem à especialização das produções, a fim de torná-las mais eficientes e, como consequência da divisão internacional do trabalho, baseada no uso de vantagens comparativas, cresceria também a oferta mundial de bens e a negociação a preços racionais assegurados pela concorrência como modo de defesa do consumidor; iii - transitoriedade da insuficiência de 
demanda: segundo a famosa Lei de Say, as mercadorias seriam produzidas para serem trocadas, motivo pelo qual, ainda que houvesse desajuste passageiro em sua representação expressa pela moeda, o mercado naturalmente corrigiria essa alocação de recursos, atingindo um equilíbrio; e, por fim, iv - máximo benefício: a não intervenção garante o funcionamento eficiente da economia, com máximo aproveitamento para cada um que persegue seu próprio interesse.

Para Leo Huberman (1986), a diversificação de produtores e a expansão dos mercados impulsionados pelo desenvolvimento dessas teorias seriam fatores de relevância que possibilitaram a transição de um sistema de produção doméstico ou familiar, de âmbito local, para um sistema de produção fabril capitalista, em âmbito internacional.

Entretanto, a constatação dessa mudança de paradigma de produção e a própria descrição do capitalismo pelo seu endosso ao modelo de produção, em si, ainda não seriam suficientes para explicar a formação do capitalismo, enquanto ideologia dotada de seus próprios valores e da potencialidade de sua adesão a nível global.

Neste sentido, guarda relevância a compreensão do sociólogo Max Weber (2004) que ressaltou a mudança profunda de mentalidade na cultura da sociedade cristã ocidental, que permitiu a consolidação do que seriam as principais crenças e práticas do capitalismo.

De certo modo, a adoção e difusão progressiva e global dessa cultura franqueou mudanças significativas de comportamento em relação à economia, em especial às atividades empresariais e financeiras impulsionadas pelo capital, bem como à própria forma de controle social do indivíduo e de suas aspirações. Como já advertia o próprio Weber (2004), já no final do século XIX, essa mudança cultural ganhou autonomia em relação ao seu fundamento ético inicial, de origem teológica, e passou a se revestir de um caráter secular e laico, inerente às instituições e estruturas administrativas do Estado moderno.

\section{A imagem de economia de mercado pelo capitalismo (neo)liberal: homo economicus e a recusa à visão humanista}

Em 2020, o mundo sofreu os flagelos da pandemia do Coronavírus, atingindo com bastante força a economia global, trazendo muitos retrocessos para o desenvolvimento de 
países latino-americanos, em especial o Brasil. Em uma reflexão nacional sobre aquele cenário, José Renato Nalini (2020) trouxe uma importante colocação sobre o dilema social e econômico brasileiro, para muito além da pandemia, sintetizado nas seguintes palavras:

\begin{abstract}
O Brasil tentou assimilar o progresso e o desenvolvimento de outros países, mas não atentou para o advento de uma sociedade de risco. Nossa evolução é inacabada, porque o Pacto Social, ideia vitoriosa desde o século XVIII, incorporou valores de uma nova ordem, alicerçada sobre o saber científico, mas não soube equilibrar o confronto economia x justiça social. (NALINI, 2020a, p.28-29).
\end{abstract}

Esta frase inaugural representa diversos pontos problemáticos do capitalismo que, na atualidade, sugere a existência de uma crise de legitimidade e de confiança, devido à grande concentração de renda existente e de uma sensação generalizada de que os mecanismos de representatividade existentes não estariam correspondendo aos anseios populares. E, como visto alhures, o não atendimento dessas expectativas políticas somadas às expectativas sobre o desenvolvimento econômico, embora ainda não represente uma ameaça imediata incontornável, caso se tornem reiteradas e constantes poderão afetar as próprias instituições democráticas, a longo prazo (HUDLER; SILVA; BENACCHIO, 2020), porquanto a ascensão da extrema esquerda representa o risco de profundo abalo às liberdades individuais conquistadas.

Subsiste, assim, uma percepção generalizada de que o grande vilão ou antagonista para o desenvolvimento social e econômico objetivado na atualidade é o próprio capitalismo. Mas, o que seria este capitalismo e qual sua relação com a economia de mercado global vivenciada na atualidade?

De fato, é recorrente o emprego do termo economia de mercado atrelado ao capitalismo, visto que o primeiro é a expressão material do segundo. Desde logo, vale indicar que, para efeitos do presente estudo, os referidos termos devem ser adequadamente diferenciados. Isso porque o pressuposto da noção de mercado é a própria ideia de estrutura pela qual se realizam as trocas de bens e a prestação de serviços, enquanto a de capitalismo integra uma gama de valores ou concepções que motivam ou direcionam a realização dessas atividades econômicas a partir do reconhecimento das liberdades individuais como atributo constitutivo da percepção jurídica da pessoa.

Neste passo, importante destacar que o mercado, em si, não estabelece uma autoridade central para organização dos fatores produtivos, muito menos elege uma determinada 
ideologia (como, por exemplo, o capitalismo liberal). Cada ator econômico é promove sua atividade de acordo com o que entende ser mais benéfico a si. Assim, a atividade econômica e o funcionamento do mercado também são projetados a partir da condensação do conjunto das manifestações econômicas tomadas dentro de uma visão cultural, política e jurídica específicas de mundo, que por sua vez não é isenta de valores (BENACCHIO, 2018).

Esclarecido este ponto é que se torna possível compreender que, a partir da pósmodernidade, foi criada uma determinada imagem de mercado, segundo a qual, consoante Marcelo Benacchio (2018), resultou em uma visão redutiva do ser humano a um aspecto muito específico e limitado, hoje em dia chamado de homo economicus, com base em uma compreensão de maximização utilitarista de interesses próprios. E essa visão, embora crua e que enalteça um sentimento de sobrevivência darwiniana, é percebido por uma parcela de autores (neo)liberais como algo natural. Tornou-se, assim, um dos instrumentos retóricos do capitalismo liberal, no qual e pelo qual o ser humano é representado sobretudo por essa imagem de mercado. Na linha do que lecionam Sayeg e Balera (2011):

\footnotetext{
Portanto, diante do elevado nível de massificação, de impessoalidade, de desarticulação para com o homo economicus, enfim, de desumanização da economia de mercado, é manifesta a vulnerabilidade a que este, enquanto presa, se acha exposto, e também fica vulnerável o planeta. Ao exaltar o individualismo e o hedonismo em nome da liberdade, o humanismo antropocêntrico acaba corroborando a primazia do dinheiro e colocando o homo economicus em segundo plano, sozinho, à mercê do poder da moeda e vítima do próprio antropocentrismo, razão pela qual há de ser conformado — jamais negado - pelo capitalismo humanista como expressão do humanismo antropofilíaco.
}

Esse capitalismo liberal, embora seja fundado teoricamente na dimensão de liberdade, coloa-se como diametralmente oposto à perspectiva dos Direitos Humanos - e, como resposta a esta visão, é que surge o Capitalismo Humanista, enquanto uma proposta de superação do mito da neutralidade entre capitalismo liberal e Direitos Humanos (SAYEG, 2020).

Evidente que esta imagem quase selvagem do capitalismo liberal, que identifica os agentes econômicos como elementos de uma mesma política contrária aos Direitos Humanos, foi severamente criticada durante o século XX.

De forma muito interessante, a essência desta crítica foi capturada em uma imagem paradigmática ocorrida em 2011, oportunidade em que um grupo de manifestantes se prostrou 
em frente ao coração financeiro do mundo, em sinal de protesto ao sistema financeiro, movimento que ficou conhecido como "Occupy Wall Street". Esse fenômeno ocorrido em solo americano, foi analisado com entusiasmo pela comunidade acadêmica, a exemplo da socióloga Heather Gautney da Fordham University que, ao testemunhar os fatos da época, afirmou:

Implícita nesta estrutura está também a rejeição da forma de liderança narcisista: "Eu sei o que é bom para você", agora difundida neste país, na qual os legisladores deixam de considerar as necessidades e desejos das pessoas que afirmam representar. O fracasso da democracia representativa nos Estados Unidos é talvez um dos problemas mais sérios de nosso tempo, e o movimento Occupy é um sintoma dessa crise de legitimidade. O povo não confia mais em seus líderes e está até começando a denunciar o próprio sistema. Eles acham que podemos fazer melhor. Somos todos líderes. (GAUTNEY, 2011, p.3, tradução nossa ${ }^{l}$ ),

No entanto, o Capitalismo Humanista, enquanto proposta de desenvolvimento como liberdade - isto é, no sentido empregado pelo economista Amartya Sen -, muito longe de rechaçar a empresa ou qualquer ator econômico que realize suas atividades no âmbito da economia de mercado, entende que esta é uma realidade e que deve ser (re)estruturada a partir de uma nova ética, integrada pela consubstancialidade quântica - isto é, que traga o capitalismo como égide dos Direitos Humanos reconhecidos internacionalmente, e que se mova no sentido de sua aplicabilidade no cotidiano, a fim de preservar o próprio capitalismo de sua mais severa crítica: a ausência de fraternidade nas relações econômicas.

Aliás, no histórico encontro entre ocidente e oriente, ocorrido em fevereiro de 2021, no $1^{o}$ Dia Internacional da Fraternidade Humana, organizado pelas Nações Unidas, o Papa Francisco, diante de autoridades de nações e representantes religiosos, sumarizou muito bem esta ideia, ao afirmar que a fraternidade é a nova fronteira da humanidade, finalizando seu discurso com uma frase icônica "Ou somos irmãos ou destruímo-nos uns aos outros." (FRANCISCO, 2021, p.1).

Em sua acepção teleológica, os Direitos Humanos estão calcados no reconhecimento dos direitos subjetivos da pessoa e do pleno desenvolvimento de sua personalidade, em direção ao bem estar. Desta feita, a singularidade que decorre dos atributos constitutivos do

\footnotetext{
${ }^{1}$ No original: "Implicit in this structure is also a rejection of the narcissistic, "I know what's good for you" form of leadership, now pervasive in this country, in which lawmakers fail to consider the needs and desires of the people they claim to represent. The failure of representative democracy in the United States is perhaps one of the most serious problems of our time, and the Occupy movement is a symptom of this crisis of legitimacy. The people no longer trust their leaders and are even starting to indict the system itself. They think we can do better. We are all leaders.".
} 
ser humano, enquanto liberdade, igualdade radical de aptidão de contrair direitos e deveres e dignidade, se tornou a medida de todas as coisas.

Eis que, pela ótica humanista, a finalidade do Direito seria a preservação de condições para sua realização pessoal pois, como sintetiza Carlos Ayres Britto (2012, p. 20):

De fato, o desenrolar do tempo tem situado o gênero humano no centro do universo. Da proclamação de que "o homem é a medida de todas as coisas" (Protágoras) ao "cógito" de René Descartes, passando pela máxima teológica de que todos nós fomos feitos à imagem e semelhança de Deus, o certo é que a pessoa humana passou a ser vista como portadora de uma dignidade inata. Por isso que titular do "inalienável" direito de se assumir tal como é: um microcosmo. Devendo-se-lhe assegurar todas as condições de busca da felicidade terrena.

Entretanto, de certo que essa informação não é um dado, e sim uma construção histórico-cultural, consagrada normativamente pela Constituição Federal de 1988. A partir dela, não mais é opcional ser humanista. Mas, o que significaria ser humanista? Uma parte do estudo sobre humanismo centraliza-se no conceito de pessoa e na compreensão sobre a posição e relevância do ser humano em relação ao universo.

Deste modo, vale recordar a compreensão de Fábio Konder Comparato (2013), que identifica uma elaboração filosófica constante sobre o tratamento filosófico e jurídico dado ao conceito de pessoa ao longo da história, sumarizada didaticamente por cinco etapas fundamentais: $1^{\text {a }}$ - da lei escrita como meio de proteção do indivíduo contra arbítrios, seja pela justificativa divina inspirada na lei escrita judaica, seja pela noção helênica de lei escrita (nomos êngraphos) e não escrita (nomos ágraphos), ou ainda com esteio na compreensão que se afastou do sagrado, centrado mais na natureza (physis), aprofundada por sofistas e estoicos; $2^{\mathrm{a}}$ - da igualdade dos homens enquanto proposta universal cristã; $3^{\circ}-$ do homem enquanto sujeito de direitos universais, anteriores e superiores ao Estado, inerente ao pensamento kantiano; $4^{\mathrm{a}}$ - pela percepção de uma vasta diversidade de preferências valorativas, em um contexto de tensão dialética; $5^{\mathrm{a}}$ - de oposição à crescente reificação das relações humanas decorrentes da industrialização e totalitarismo (século $\mathrm{XX}$ ), refletido no pensamento existencialista.

Essa visão humanista geral, por outro lado, não pode ser confundida com o humanismo antropocêntrico, que torna centrais e absolutos os interesses individuais do ser humano, a despeito do próximo. Como sugere Sayeg e Balera (2011) aquela medida de todas 
as coisas indicada inicialmente - que traz o homem para o centro do universo, o qual deve ser servido e satisfeito em seus interesses de maneira individualista, hedonística e ilimitada deve ser rechaçada e evoluída para uma visão humanista antropofilíaca.

Sobre essa contraposição de ideias no seio do próprio humanismo, descrevem os autores:

\begin{abstract}
A máxima antropocêntrica de que "o homem é a medida de todas as coisas" é atribuída a Protágoras; porém, "na Antiguidade os homens são valorizados por suas posses, qualidades e por seus feitos heroicos, não se incluindo nessa concepção os pobres, as mulheres e os escravos". Esse modo de ver, com traços humanistas, referia-se ao homem "contanto que seja cidadão", como ressalvou Aristóteles, dissociando-o da integralidade do gênero humano, em especial dos menos favorecidos materialmente. Jesus Cristo vai além e, com sua mensagem de fraternidade universal, instaura o humanismo antropofilíaco em face de todo o gênero humano, que é decifrado para o direito em sua concepção de direito natural com os ensinamentos aristotélicos de São Tomás de Aquino (...) (SAYEG; BALERA, 2011, p. 63).
\end{abstract}

De fato, grande destaque se deu àquela etapa relacionado ao cristianismo, principalmente por inaugurar uma pretensão universal de igualdade radical a todos, de intenso impacto cultural para a humanidade, a tal ponto que, por Ricardo Sayeg e Wagner Balera (2011), é sustentada a tese no sentido de existir uma norma universal com esteio na fraternidade, fundamentada antropologicamente pelo amor de Jesus Cristo, que conduz com a liberdade e igualdade em direção à democracia e à paz.

\title{
4. A incorporação da proposta ética do Capitalismo Humanista pelo ordenamento jurídico brasileiro
}

De modo geral, tanto as condutas quanto a própria produção normativa, enquanto partes integrantes da realidade social, são balizadas a partir de valores insculpidos nos princípios, com os quais interagem reflexivamente ${ }^{2}$ (PERLINGIERI, 2002). Esses princípios

\footnotetext{
${ }^{2}$ A esse respeito, Perlingieri $(2002$, p. 2): "O conjunto de princípios e de regras destinado a ordenar a coexistência constitui o aspecto normativo do fenômeno social: regras e princípios interdependentes e essenciais, elementos de um conjunto unitário e hierarquicamente predisposto, que pode ser definido, pela sua função, como 'ordenamento' (jurídico), e, pela sua natureza de componente da estrutura social, como 'realidade normativa'. A
} 
constituem a estrutura do ordenamento jurídico, os quais, portanto, não podem ser negligenciados em sua aplicação, sob pena de se prejudicar a própria unidade do ordenamento.

No caso do ordenamento jurídico brasileiro há uma proposta ética apresentada pela Constituição Federal de 1988, enquanto opção política, que elege determinados valores orientadores da conduta humana e da produção normativa que neles se inspira.

A CF/1988, de forma mais específica e temática, estrutura a economia a partir de normas jurídicas, enquanto fundamentos, fim e princípios. Estes são dotados de um conteúdo ético, pois possuem, para além da capacidade de determinar a elaboração de outras normas jurídicas infraconstitucionais sobre o tema, o condão de orientar condutas, destacar a finalidade e os objetivos que se pretende atingir enquanto sociedade, a partir da eleição de valores específicos, os quais trazem um conteúdo mínimo e possíveis limites para atividade empresarial. Em síntese a esse pensamento, afirma Luís Roberto Barroso (2013, p.226): "são a porta pela qual os valores passam do plano ético para o plano jurídico".

Sob ponto de vista estritamente normativo, desde o preâmbulo da Constituição é que se elege como ideal a ser perseguido a sociedade fraterna ${ }^{3}$, e os respectivos objetivos traçados no $\operatorname{artigo} 3^{\circ}$.

No âmbito constitucional, a atividade econômica possui uma regulação jurídica que se inicia a partir da chamada Constituição Econômica, estabelece uma determinada ordem (jurídica) da economia, por meio de uma organização de instituições relacionadas às relações econômicas, inclusive a atividade empresarial.

transformação da realidade social em qualquer dos seus aspectos (diversos daquele aspecto normativo em sentido estrito) significa a transformação da 'realidade normativa' e vice-versa. A afirmação, ao contrário, da autonomia da ciência jurídica e as conseqüentes tentativas de definir a chamada 'realidade jurídica' como alguma coisa que possa viver separadamente da realidade social, econômica ou política é herança que ainda pesa muito sobre os juristas e sobre o ensino do Direito. Isso levou à criação de uma cultura formalista, matriz de uma 'teoria geral do direito' sem (explícitas) 'infiltrações' de caráter político, econômico, sociológico: como se o direito fosse imutável, eterno, a-histórico, insensível a qualquer ideologia.”.

${ }^{3}$ Como disposto na Constituição Federal de 1988: "Nós, representantes do povo brasileiro, reunidos em Assembléia Nacional Constituinte para instituir um Estado Democrático, destinado a assegurar o exercício dos direitos sociais e individuais, a liberdade, a segurança, o bem-estar, o desenvolvimento, a igualdade e a justiça como valores supremos de uma sociedade fraterna, pluralista e sem preconceitos, fundada na harmonia social e comprometida, na ordem interna e internacional, com a solução pacífica das controvérsias, promulgamos, sob a proteção de Deus, a seguinte CONSTITUIÇÃO DA REPÚBLICA FEDERATIVA DO BRASIL”.

${ }^{4}$ Como previsto na Constituição Federal de 1988: "Art. $3^{\circ}$ Constituem objetivos fundamentais da República Federativa do Brasil: I - construir uma sociedade livre, justa e solidária; II - garantir o desenvolvimento nacional; III - erradicar a pobreza e a marginalização e reduzir as desigualdades sociais e regionais; IV - promover o bem de todos, sem preconceitos de origem, raça, sexo, cor, idade e quaisquer outras formas de discriminação.". 
Neste pasto, a CF/1988 sistematizou os principais elementos de uma Constituição Econômica de modo a concentrá-los em um título específico para a ordem econômica e financeira (Título VII), inaugurando princípios gerais da atividade econômica (Capítulo I), delineados no art. $170^{5}$, os quais sugerem a realização de uma hermenêutica para as relações econômicas, sem descurar que esta deverá ser realizada também em consonância com o todo (SOUZA, 1989).

Vale enfatizar que esses princípios não pretendem proteger a atividade do setor público ou do setor privado em si, o Estado ou a empresa, o empresário ou o trabalhador, pois, o que se pretende é uma tutela multidimensional que, fundada na valorização do trabalho humano e na livre iniciativa, visa garantir a tudo e a todos uma existência digna, enquanto expressão de um interesse universal, conforme se extrai dos princípios indicados pelo artigo 170, da CF/1988. Como bem pontuam Sayeg e Balera (2011, p. 156 -157):

\begin{abstract}
A referência, no Artigo 174 da Constituição Federal, aos setores público e privado da economia, não limita a ordem econômica a tais setores, que são público e privado frente aos agentes econômicos, não face aos tutelados pela ordem econômica — que são todos e tudo. Logo, o que se verifica é que a ordem econômica rege os setores privado e público da economia, isto é, tendo os particulares e o Estado como agentes econômicos, o que não se confunde com a tutela multidimensional incidente, a partir do Direito Econômico, com o fim de garantir a todos uma existência digna, tal como consta do caput do Artigo 170 da Constituição Federal. Enfaticamente, por força da Lei Universal da Fraternidade aplicada ao capitalismo, o fim da ordem econômica é a concretização dos direitos humanos em todas as suas dimensões em cadeia de adensamento, assegurando vida plena ao homem livre e a todos os homens do planeta: é a busca do correspondente objeto da dignidade da pessoa humana e planetária. Desse fim se depreende que a ordem econômica não está a tutelar nem só o interesse privado, nem só o interesse público, mas a todos e a tudo, incluindo o interesse universal.
\end{abstract}

Ademais, o olhar que a sociedade também lança sobre a função social da empresa deve ser no sentido de sua preservação e estímulo, e não propriamente de embate, visto que, como fundamento por Balera (2020, p.1-2):

\footnotetext{
${ }^{5}$ Neste sentido é que se apresenta a norma constitucional, cuja reprodução é válida e norteia a compreensão do tema: "Art. 170. A ordem econômica, fundada na valorização do trabalho humano e na livre iniciativa, tem por fim assegurar a todos existência digna, conforme os ditames da justiça social, observados os seguintes princípios: I - soberania nacional; II - propriedade privada; III - função social da propriedade; IV - livre concorrência; V defesa do consumidor; VI - defesa do meio ambiente, inclusive mediante tratamento diferenciado conforme o impacto ambiental dos produtos e serviços e de seus processos de elaboração e prestação; VII - redução das desigualdades regionais e sociais; VIII - busca do pleno emprego; IX - tratamento favorecido para as empresas de pequeno porte constituídas sob as leis brasileiras e que tenham sua sede e administração no País. Parágrafo único. É assegurado a todos o livre exercício de qualquer atividade econômica, independentemente de autorização de órgãos públicos, salvo nos casos previstos em lei” (BRASIL, 1988).
} 
No âmbito do Capitalismo Humanista, a empresa assume papel fundamental porque lhe incumbe, em primeiro lugar, ter por escopo garantir a dignidade do trabalhador. Essa é a primeira função social da empresa: garantir a dignidade da pessoa humana do trabalhador. (...) Também a empresa cumpre sua função social quando produz com qualidade, isto é, presta à comunidade bons serviços, gerando com qualidade aquilo que se compromete a fazer. Não apenas inspirada no animus lucrandi, normal da atividade da empresa, mas também na função social de bem servir à comunidade. A empresa cumpre sua função social de bem servir a comunidade, conforme os ditames da Constituição, quando patenteia com idoneidade os produtos que apresenta.

Em auxílio a uma leitura mais atenta sobre essa ordem econômica, interessante a proposta de distinção semântica formulada por Washington Peluso Albino de Souza (1989), de que fundamento seria a razão de uma preferência, a causa, e princípio, por sua vez, um ponto de partida do processo interpretativo. Assim é que os fundamentos da ordem econômica - de um lado, a valorização do trabalho humano e, de outro, a livre iniciativa - conectam-se com os objetivos pretendidos pela própria $\mathrm{CF} / 88$, notadamente o de assegurar a todos uma existência digna, enquanto os princípios dela emanados - como soberania nacional, propriedade privada, função social da propriedade, livre concorrência, defesa do consumidor, defesa do meio ambiente - serviriam como vias condutoras para efetivação dessa ordem.

De fato, é notório que todas as normas têm, como teleologia, o supraprincípio da dignidade humana, de tal modo que não se pode pretender a realização de qualquer princípio sem que se considere também a dignidade como questão ética central (BARROSO, 2013; NALINI, 2020b). Como ressaltado por Nalini (2020b, p.15):

\footnotetext{
O tema dignidade está presente na República do Brasil, desde que foi inspiração do constituinte para pavimentar toda a vida pública. É o supraprincípio irrecusável, que depende de cada um ser efetivamente observado. Tanto que autonomia e dignidade são intrinsecamente relacionadas e mutuamente imbricadas, como pondera Thadeu Weber: "A dignidade pode ser considerada como o próprio limite do exercício do direito de autonomia. E este não pode ser exercido sem o mínimo de competência ética".
}

Nesta senda, pelo destaque constitucional conferido à dignidade, funda-se uma ordem econômica que não se resume aos imperativos e valores do capitalismo liberal, tampouco de imposições econômicas pela economia global, mas sim a adoção normativa pelos valores de um capitalismo humanizado, a partir de uma perspectiva jus humanista sobre o Direito 
Econômico, que parte da normativa estruturada pelos Direitos Humanos, o qual emprega a consubstancialidade quântica de estruturas de liberdade, igualdade e fraternidade como sustentáculos, direcionado inclusive para a atividade econômica desempenhada pelas Empresas Transnacionais ${ }^{6}$ (SAYEG; ARRUDA JUNIOR, 2016).

\section{Considerações Finais}

Pela exposição, pode-se aduzir que:

1 - o capitalismo liberal, enquanto modelo econômico representativo da liberdade, reclama evolução e significa ponto de vista superado pela resposta às críticas quanto às suas externalidades negativas;

2 - o capitalismo, de forma ampla, não se esgotou, embora tenha se originado em uma forte percepção de matiz (neo)liberal que refuta os dilemas humanistas que necessitam de solução no contexto da pós-modernidade;

3 - A Constituição Federal de 1988 dá resposta aos dilemas humanistas do capitalismo ao incorporar os valores do Capitalismo Humanista, a partir de uma proposta ética universalista presente desde o seu preâmbulo, em especial ao estabelecer no seu artigo 170, um modelo da dimensão econômica da sociedade fraterna que visa edificar conforme os objetivos fundamentais estatuídos no seu artigo $3^{\circ}$.

\footnotetext{
${ }^{6}$ Consoante síntese de Sayeg e Arruda Júnior (2016, p.331-332): “Em assim sendo, se analisada corretamente a estrutura jurídica do capitalismo no Brasil, forçoso reconhecer que a disciplina jurídica do capitalismo adotada na Constituição Federal não é o capitalismo liberal, nem o capitalismo que fundamenta a globalização econômica, mas sim um capitalismo humanista, no sentido de reconhecer a supremacia dos direitos humanos sobre a ordem jurídica nacional, numa perspectiva humanista do Direito Econômico. Exatamente neste último aspecto que reside o capitalismo humanista: por meio do marco teórico da fraternidade, baseado numa filosofia 'jus humanista' que adota o adensamento das estruturas de liberdade, igualdade e fraternidade como sustentáculo de um capitalismo em prol da humanidade. Oportuno também enfatizar que, ao reconhecer a propriedade e a liberdade como direitos naturais, a partir da visão de Locke, certo é que o capitalismo humanista se harmoniza com o humanismo antropofiliaco e com a Lei Universal da Fraternidade, aspectos jurídicos e filosóficos que permeiam as relações econômicas. Por isso que as empresas transnacionais devem respeitar a ordem jurídica capitalista humanista, para que suas atividades econômicas estejam de acordo com a Constituição Federal e respectiva ordem econômica constitucional, especialmente, na inserção dos direitos humanos em todas as suas dimensões nas suas relações internas e externas, a bem de tudo e de todos, sem qualquer tipo de exclusão. Do ponto de vista prático é difícil, mas não impossível, que as empresas transnacionais e respectivos dirigentes e colaboradores sigam as diretrizes constitucionais, cabendo encontrar uma forma prática e eficiente na rotina da empresa, de inserir a principiologia capitalista humanista recepcionada pela Constituição Federal nas suas atividades econômicas e em todas as suas relações internas e externas.".
} 


\section{REFERÊNCIAS BIBLIOGRÁFICAS:}

BALERA, W. A empresa e o Capitalismo Humanista. O Estado de S. Paulo, São Paulo, Dez./2020. Disponível em: https://politica.estadao.com.br/blogs/fausto-macedo/a-empresa-eo-capitalismo-humanista/. Acesso em: 15 abr. 2021

BARROSO, L. R. Curso de Direito Constitucional Contemporâneo. 4. ed. São Paulo: Saraiva, 2013.

BENACCHIO, M. A ordem jurídica do mercado na economia globalizada. In: LEMOS JORGE, A. G.; ADEODATO, J. M.; DEZEM, R. M. M. (Org.). Direito Empresarial, vol. 1. São Paulo: UNINOVE, 2018, p. 27-46.

BRITTO, C. A. O humanismo como categoria.1. ed. Belo Horizonte: Fórum, 2012.

COMPARATO, Fábio Konder. A afirmação histórica dos Direitos Humanos. 8. ed. São Paulo: Saraiva, 2013.

FARIA, J. E.; KUNTZ, R. Qual o futuro dos direitos?: Estado, mercado e justiça na reconstrução capitalista. São Paulo: Max Limonad, 2002.

FRANCISCO. $1^{\circ}$ Dia Internacional da Fraternidade Humana: mensagem em vídeo do Papa Francisco. Vaticano, Santa Sé, 4 fev. 2021. Disponível em:

http://www.vatican.va/content/francesco/pt/messages/pont-messages/2021/documents/papafrancesco_20210204_videomessaggio-giornata-fratellanza-umana.html. Acesso em: 15 abr. 2021.

GAUTNEY, H. What is Occupy Wall Street? The history of leaderless movements.

Washington Post. oct./2011. Disponível em: https://www.washingtonpost.com/national/onleadership/what-is-occupy-wall-street-the-history-of-leaderless-

movements/2011/10/10/gIQAwkFjaL_story.html. Acesso em: 15 abr. 2021.

HUBERMAN, L. História da riqueza do homem. Tradução: W. Dutra. 21 ed. Rio de Janeiro: LTC, 1986.

HUDLER, D. J.; SILVA, V. de L.; BENACCHIO, M Credibilidade na Democracia: o declínio de confiança como risco às instituições e ao desenvolvimento econômico. In: I

ENCONTRO VIRTUAL DO CONPEDI, 2020, Florianópolis. Teorias da democracia e direitos políticos e Filosofia do Estado II. Florianópolis: CONPEDI, 2020. v. 1. p. 68-84.

NALINI, J. R. Uma nova formatação da ética. In: CUNHA FILHO, A. J. C.; ARRUDA, C. S. L. de A.; ISSA, R. H.; SCHWIND, R. W. (Orgs.). Direito em Tempos de Crise: Covid-19, Vol.1. 1. ed. São Paulo: Quartier Latin, 2020a. 
NALINI, J. R. Ética Geral e Profissional. 14. ed. São Paulo: Revista dos Tribunais, 2020b.

SAYEG, R. H. O capitalismo humanista é a esperança. Mar./2020. Disponível em: https://www.migalhas.com.br/depeso/322798/o-capitalismo-humanista-e-a-esperanca. Acesso em 15 abr. 2021.

SAYEG, R. H.; ARRUDA JUNIOR, A. C. M. de. O Capitalismo Humanista aplicado nas Empresas Transnacionais. In: BENACCHIO, M.(coord.); VAILATTI, D. B.; DOMINIQUINI, E. D. (orgs.). A sustentabilidade da relação entre empresas transnacionais e Direitos Humanos. Curitiba: CRV, 2016.

SAYEG, R. H.; BALERA, W. O Capitalismo Humanista. Petrópolis: KBR, 2011.

SOUZA, W. P. A. de. A experiência brasileira de Constituição Econômica. Revista Informação Legislativa, Brasília, ano 26, n. 102, abr./jun. 1989.

WEBER, M. La ética protestante y el espíritu del capitalismo. Trad.: Joaquín Abellán. 1. Ed . Madrid: Alianza Editorial, 2004.

WORLD BANK. Life expectancy at birth, total (years), 2021. Disponível em: https://data.worldbank.org/indicator/SP.DYN.LE00.IN. Acesso em 15 abr. 2021. 